\title{
The Role of Gender as Moderator between Cognitive-Emotional Regulation Strategies and Internalizing/Externalizing Behavioural Problems among Adolescents
}

\author{
Vahid Momtaz (Corresponding author) \\ Department of Human Development and Family Studies \\ University Putra Malaysia, Malaysia \\ vmomtaz@yahoo.com \\ Mariani BTE Mansor \\ Department of Human Development and Family Studies \\ University Putra Malaysia, Malaysia \\ Mansor Abu Talib \\ Department of Human Development and Family Studies \\ University Putra Malaysia, Malaysia \\ Rojanah BT Kahar \\ Faculty of Human Ecology \\ University Putra Malaysia, Malaysia
}

\begin{abstract}
Internalizing/externalizing behavioural problems among adolescents are the most important issue in adolescents' mental health. Cognitive-emotional regulation strategies are the important protective and risk factor for internalizing/externalizing behavioural problems. In the present study the moderating role of gender in the relationship between cognitive-emotional regulation strategies and internalizing/externalizing behavioural problems among adolescents was investigated. The respondents were 328 students who filled out Youth Self Report and Cognitive-Emotional Regulation Questionnaire. The moderating effect of gender were estimated by AMOS and the model fit indicated that gender did not have any significant moderating role in the relationship between positive and negative cognitive-emotional regulation strategies and internalizing/externalizing behavioural problems among adolescents.
\end{abstract}

Keywords: internalizing/externalizing, cognitive-emotional regulation, gender, adolescents

\section{Introduction}

Internalizing/externalizing behavioural

problems (IEBP) is the most widespread form of mental disorders among children and adolescents. (Oshri, Rogosch, Burnette, \& Cicchetti, 2011). The studies reported that one of four or five adolescents face with IEBP, which is a considering statistics (Wright,
Jorm, \& Mackinnon, 2011; Fakhari et al, 2007). However, the research reported different statistic about the prevalence of IEBP among two genders. Graves et al (2010) in a review of papers showed that females likely are doubled in the rate of internalizing compared to males. Also, Zelomke and Hahn (2010) in a research on 1080 respondent 
between 18 and 28 years old in USA reported that internalizing was nearly doubled in females compare males. However, their sample was consisted of young adult and did not cover the adolescence period. Emami et al, (2007) reported that while around 30 percent of boys revile IEBP symptoms, just less than 20 percent of girls are diagnosed as IEBP cases. Also, Fakhari, et al (2007) reported IEBP among boys by 20 percent, and it decrease to around 9 percent in girls between 14 and 18 years old. On the other hand, Silverman and Field (2011) by reviewing some articles concluded that there is no significant difference in suffering from internalizing regard to the gender of respondents.The differtiation in the statistics about IEBP is regard to several factors auch as different methodology, instrumentaion, and cultural consideration (Gartner, 2011; Lei, Simons, Simons, \& Edmond, 2014).

One of the factors that is important in suffering from IEBP is cogitive-emotional regulation strategies (CERS) (Garnefski, Kraaij, \& Spinhoven, 2001). CERS is defined as the cognitive strategies people use to interpret their emotions (Garnefski et al, 2001). Although Garnefski, divided CERS into 9 subscales, some other researchers categorized all these 9 subscales into two major categories, named positive CERS, and negative CERS Erk et al, 2010; Monika et al,
2013). While positive CERS are considered as the protective factor against IEBP, negative CERS is a risk factor for mental health (Karim, Sharafat, \& Mahmud, 2014). Noticeably, "refocus on planning", "acceptance", "positive refocusing”, "positive reappraisal", and "putting in to perspective" are considered as the positive strategies, while 'self-blame”, “other-blame”, "rumination", and "catastrophizing" as the negative strategies of cognitive emotional regulation. Muller, Vascotto, Konanur, \& Rosenkranz (2013) in their study suggested that children with negative CERS demonstrated higherlevel of IEBP than whom utilized positive CERS. Likewise, Kim-Spoon, Cicchetti, and Rogosch (2013) according to their study reported that children and adolescents with negative CERS showed higher levels of IEBP. Although it is suggested that negative CERS lead the adolescents toward IEBP, it is not clear whether negative CERS suffers both genders equally. While some research reported different rates of utilizing negative CERS in two genders (Zlomke \& Hahn, 2010), some others claimed that there is no differences in using negative CERS across the genders (McRae, Ochsner, Mauss, Gabrieli, \& Gross, 2008; Karim et al., 2014).

According to Zelomke and Hahn (2010) in research on 1080 under graduate students of one of southern universities in USA, boys 
utilized significantly other blame strategy of negative CERS more than girls, while girls demonstrated significant more utilization of rumination than boys. There were no significant differences in the other negative strategies between two genders. In positive strategies, two genders showed not significant differentiation except for putting into perspective in which the females were scored higher than males significantly. In another study Karim et al (2014) regard to their research on 206 children aged between 12 and $15(40 \%$ boys, $60 \%$ girls) from four secondary schools that was chosen randomly in Dhaka City of Bangladesh reported that there were no significant differences between two genders in applying positive and negative CERS. They, also, stated that family status and socioeconomic condition could not make significant differences in using positive or negative CERS among the respondents. Furthermore, Mc Rae et al (2008) in an experimental study about electromagnetic changes in cognitive-emotional regulation on
25 participants aged 18-22, did not find significant differences between two genders. The above mentioned research not only resulted differently, but also did not covered adolescence period of life completely.Therefore, this study tries to address this gap by evaluating the moderating role of gender in the relationship between negative CERS and IEBP among adolescents between 12 and 19 years old.

\section{Method}

Totally, 328 students from Fars province of Iran who were selected randomly participated in this study. Respondent ages ranged from 12 to 19 years old, with an average age of 15.42 $\mathrm{SD}=1.49, \min =12$ and $\max =19$. Of the total number of respondents, $60.4 \%$ respondents were girls $(\mathrm{N}=198$ Mean=15.67 $\mathrm{SD}=4.57$ $\min =12 \max =19$ ) and $39.6 \%$ of sample were boys $(\mathrm{N}=130$ Mean=16.21 $\mathrm{SD}=4.18 \mathrm{~min}=14$ $\max =18)($ see Table 1$)$. 
Journal of Educational, Health and Community Psychology

Table 1

Description of Demographic Characteristics

\begin{tabular}{lccc}
\hline \multicolumn{1}{c}{ Variable } & $\mathrm{n}$ & $\%$ & Mean \\
\hline $\begin{array}{c}\text { Gender } \\
\text { Male }\end{array}$ & 130 & 39.6 & \\
$\quad$ Female & 198 & 60.4 & \\
Age & & & \\
$12-14$ & $80(26 \mathrm{M}, 54 \mathrm{~F})$ & 24.4 & \\
$15-16$ & $169(71 \mathrm{M}, 98 \mathrm{~F})$ & 51.5 & 15.4 \\
$17-19$ & $79(33 \mathrm{M}, 46 \mathrm{~F})$ & 24.1 & \\
\hline
\end{tabular}

Instruments

Youth Self Report (YSR; Achenbach, 1991)

IEBP was measured via Youth Self-Report (YSR, Achenbach TM, 1991) with 113 items, which was targeted for adolescents between 11-18-year-old. The Items are on different kinds of problems, and scored as follows: 0 untrue, 1 somewhat true, 2 very true or often true. The YSR can be scored on the sum of all problem scores, or the following five subscales: anxious/depressed, withdrawn, and somatic complaints (Internalizing Problems); aggressive behaviour and delinquency (externalizing problems); social problems; thought problems; and attention problems (which are not part of either the internalizing or externalizing scale). In the present study just internalizing section and externalizing section were applied for the respondents. Noticeably, the Persian version of YSR was prepared by the Achenbach the National Child Traumatic Stress network (NCTSN) and reported acceptable reliability of this instrument. To determine the validity of the questionnaire for this study, confirmatory factor analysis (CFA) was applied by AMOS 20. According to the CFA results, all items in both internalizing and externalizing subscales had acceptable factor loading (>.05). The model indices also demonstrated good model fitting for both internalizing and externalizing, except for GFI which is .88 (see Table 2).However, according to Markus(2012), if three indices are fitted, the model is acceptable. The alpha 
Journal of Educational, Health and Community Psychology

coefficient of YSR was .94 in the present study.

Table 2

CFA Model Fit Indices

\begin{tabular}{ccccccc}
\hline Model & CMIN/DF & GFI & CFI & TLI & IFI & RMSEA \\
\hline Internalizing & 2.23 & .88 & .93 & .92 & .92 & .06 \\
Externalizing & 2.09 & .88 & .91 & .90 & .91 & .06
\end{tabular}

Cognitive Emotional Regulation Questionnaire (CERQ, Garnefski, Kraaij, \& Spinhoven, 2002)

The CERQ is a self-report 36-item that covers nine subscales. In the present study just the negative subscales were utilized. These subscales consist of 16 items in 4 categories: self-blame, other-blame, rumination, and catastrophizing. Each scale consists of four items which is measured on a five point Likert scale. The Persian version of CERQ were prepared by Samani and Sadeghi (2010). They reported

\section{Data preparation}

Analysing

To analyse the hypothesized moderating role of gender in the relationship between negative CERS and IEBP, the structural equation modeling (SEM) by AMOS (20) software were applied. According to alpha coefficient reliability for all subscales of CERQ between 0.079 and 0.91. In the present study the coefficient alpha was 0.90 for total subscales of negative CERQ. Also CFA were applied for negative CERQ and the results demonstrated that all indices were fitted acceptably (Relative $\chi^{2}(<=5)=2.39$, $\operatorname{RMSEA}(<=.08)=.06, \operatorname{GFI}(>=.90)=.92$, CFI $(>=.90)=.93$, TLI $(>=.90)=.94$, IFI $(>=.90)=.92)$.

Abdollahi, Talib, Yaacob, and Ismail(2015) SEM, compare other statistical strategies run by SPSS) has more advantages. Abdollahi et al, (2015) debated that SEM enhance statistical estimation, because it accounts the measurement errors. Also this method tests multiple relations simultaneously. Finally, 
Journal of Educational, Health and Community Psychology

this strategy evaluates complex models for testing moderating or mediating effects.

At the first step, all the constructs (negative CERS, internalizing, and externalizing) were parcelled. Parcelling is a measurement strategy in SEM which is applicable in several situations such as big sample necessity problems, unreliability, and great number of indicators(Hall, Snell, \& Foust, 1999). In the present study, we parcelled regard to the great number of indictors. Noticeably, parcelling can apply by several strategies, but the common methods are parcelling based on item factor loading in each latent variable, and parcelling regard to exploratory factor analysis (EFA)(Little, Cunningham, Shahar, \& Widaman, 2002). In this study parcelling was applied according to EFA.

\section{Measurement Model}

In the second step measurement model was generated. This model involved positive cognitive-emotional regulation strategies, negative cognitive-emotional regulation strategies, and internalizing/externalizing behavioural problems as the latent variables. The goodness fit of model revealed acceptable model indices $(\mathrm{CMIN} / \mathrm{DF}=2.57, \quad \mathrm{GFI}=.87, \quad \mathrm{CFI}=.93$, $\mathrm{TLI}=.92, \mathrm{RMSEA}=.07$ ) (Figure 1Figure 1. Measurement model).

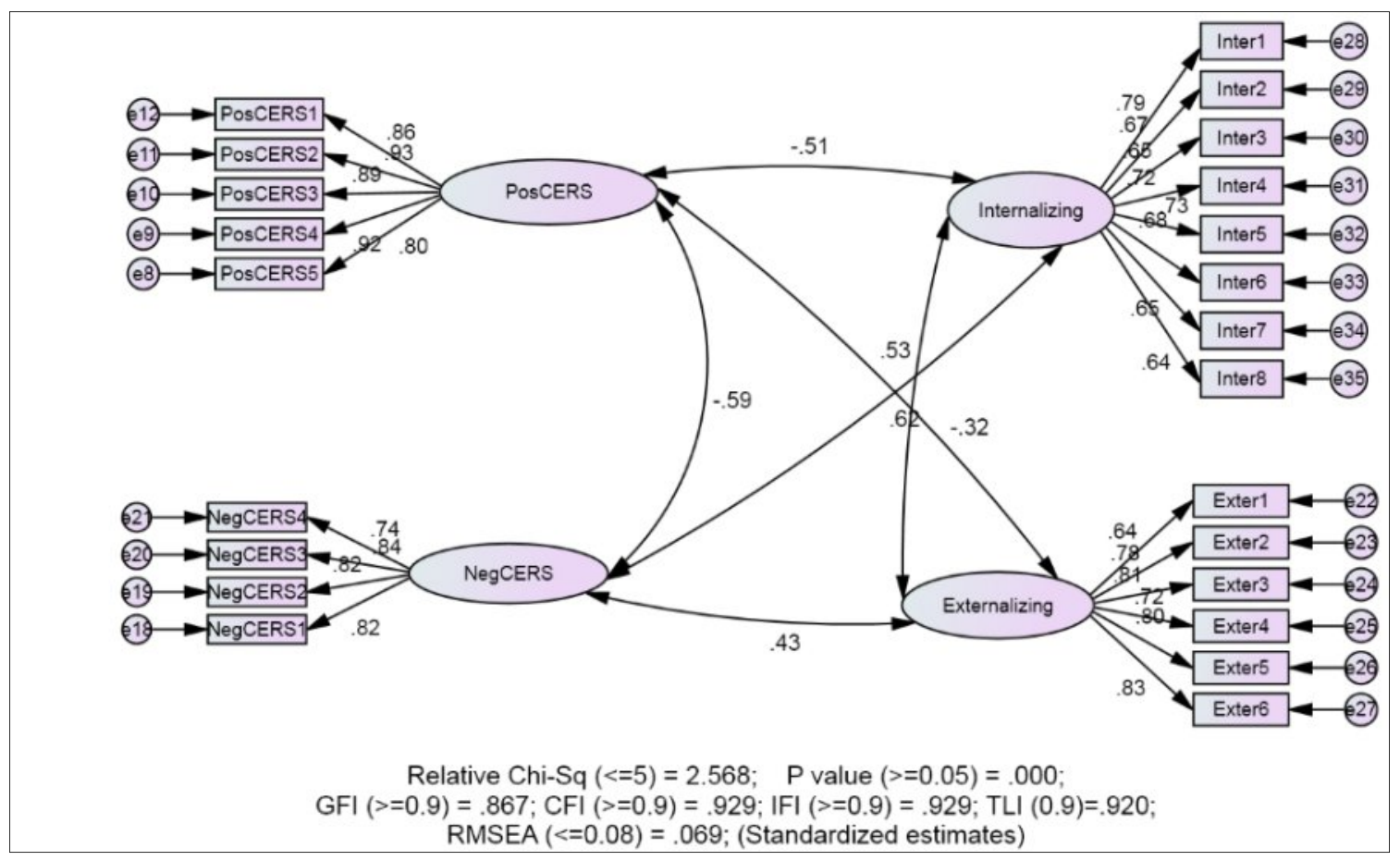

Figure 1. Measurement model 
Journal of Educational, Health and Community Psychology

\section{Structural Model}

This model included positive cognitiveemotional regulation strategies (positive CERS), and negative cognitive-emotional regulation strategies (negative CERS) as exogenous variables; internalizing and externalizing behavioural problems (IEBP) were endogenous variables. As it is demonstrated in Figure 2Positive CERS, and negative CERS, had significant relationship with both internalizing behavioural problems, and externalizing behavioural problems. According to data in figure 1 positive CERS had negative relationship with both internalizing and externalizing behavioural problems, while negative CERS showed positive relation with internalizing and externalizing behavioural problems.

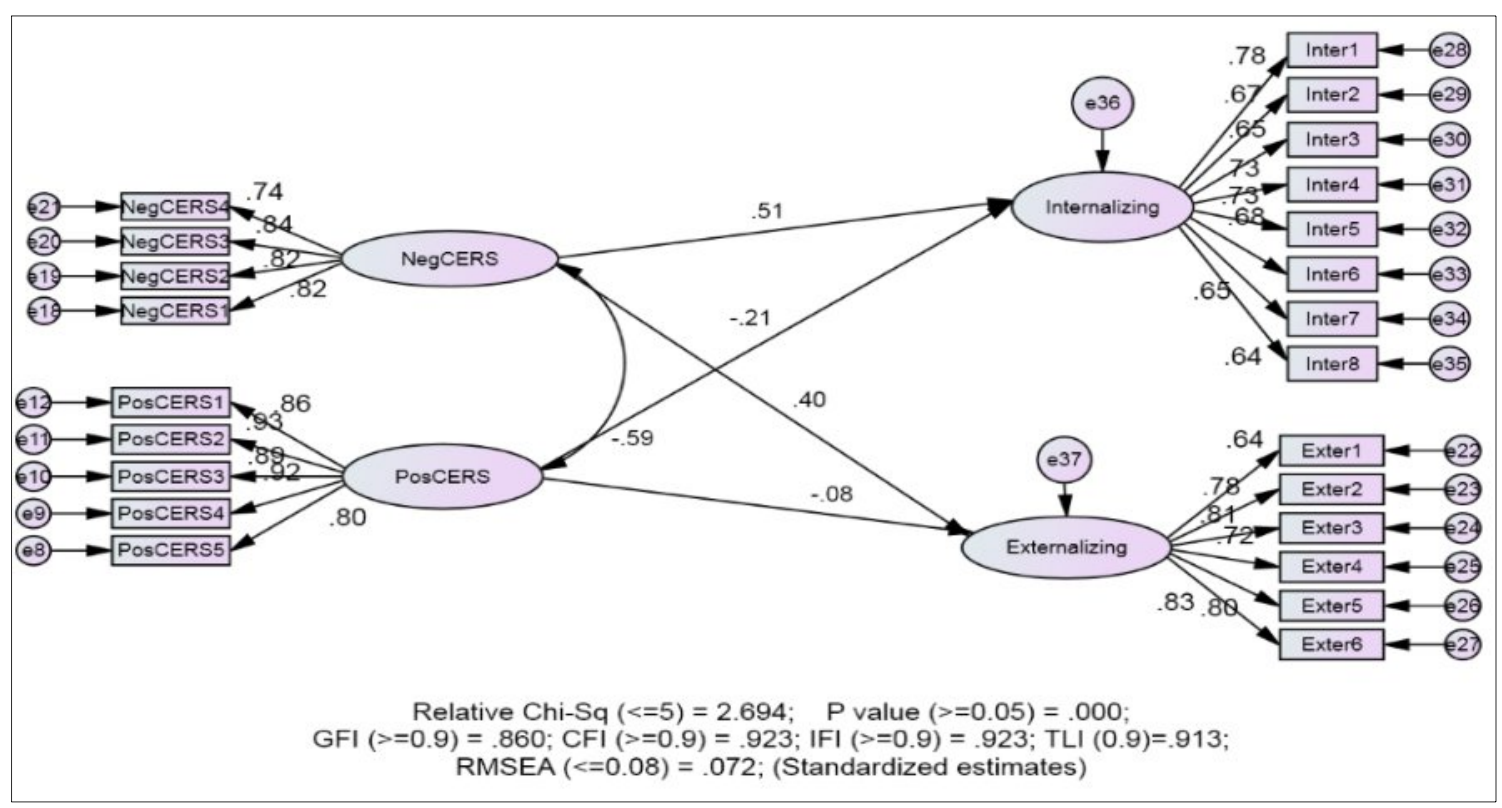

Figure 2.Structural model of IEBP. Exogenous variables including : negative CERS, and positive CERS.

Moderating role of Gender in the relationship between negative CERS and IEBP

To evaluate the moderating role of variables via SEM, the indices of "invariant group model" and "variant group model should be compared.The comparison demonstrated that both variant and invariant group model were significant, nonetheless; the invariant (unconstraint)group model was more fitted than invariant (Measurement residuals) 
Journal of Educational, Health and Community Psychology

group model, since its relative chi-square was smaller than invariant (591.79 for invariant and 737.07 for variant group

Table 3

Model Indices for Invariant and Variant Group Model

\begin{tabular}{cccccccccc}
\hline & CMIN & DF & P & CMIN/DF & GFI & CFI & TLI & IFI & RMSEA \\
\hline Invariant & 591.79 & 252 & .00 & 2.35 & .84 & .90 & .87 & .90 & .06 \\
Variant & 737.07 & 297 & .00 & 2.48 & .80 & .87 & .86 & .87 & .07 \\
\hline
\end{tabular}

To conclude the moderating effect of a externalizing were significant (see Table 4, gender variable, one of the genders should Figure 3, and Figure 4). demonstrate significant $\mathrm{p}$ value, while Consequently, gender has not moderated another one should not show significant $p$ value. The results showed that $p$ values for the relationship between negative CERS and IEBP. both gender in internalizing and

Table 4

Estimation of Moderating Role of Gender

\begin{tabular}{lccccc}
\hline \multirow{2}{*}{ Internalizing } & & Estimate & S.E. & C.R. & P \\
\hline \multirow{3}{*}{ Externalizing } & Male & .47 & .12 & 2.60 & .00 \\
& Female & .17 & .03 & 5.92 & .00 \\
& Male & .18 & .07 & 2.60 & .01 \\
\hline
\end{tabular}


Journal of Educational, Health and Community Psychology

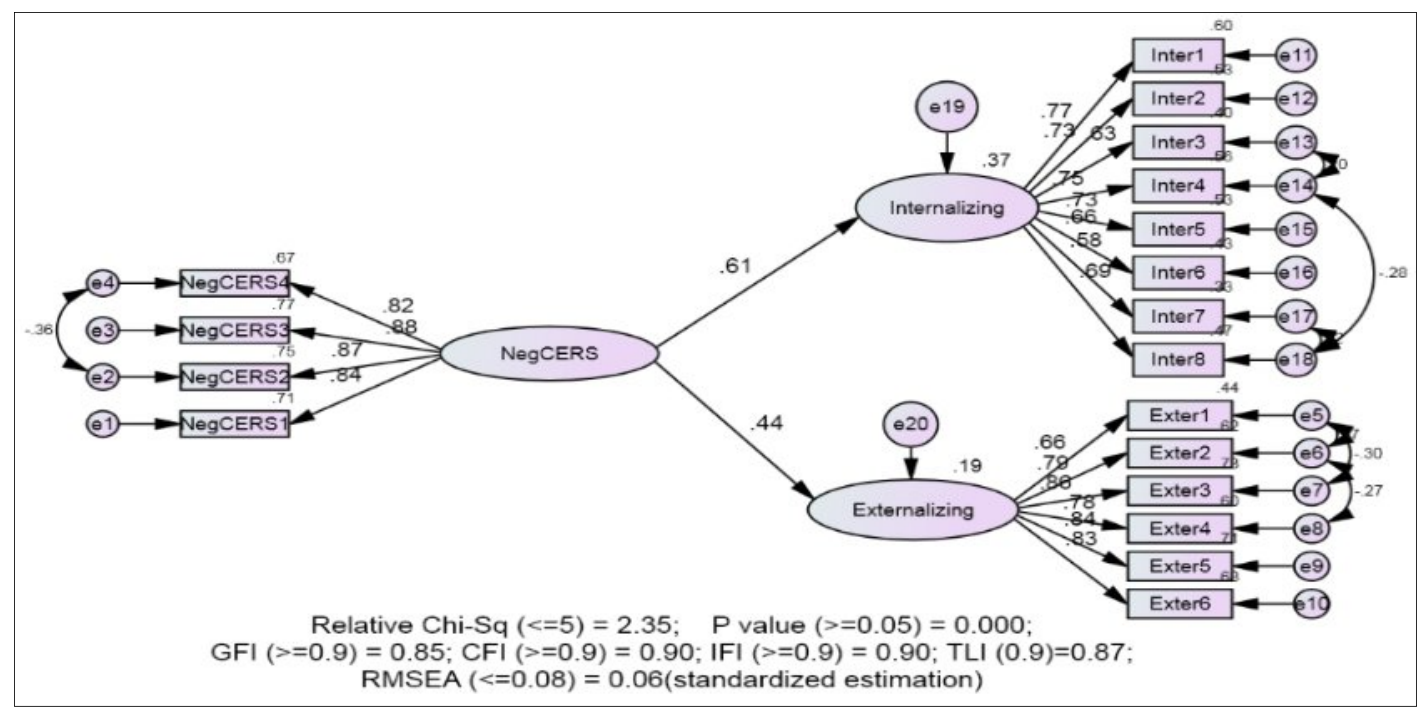

Figure 3. Model fit for females

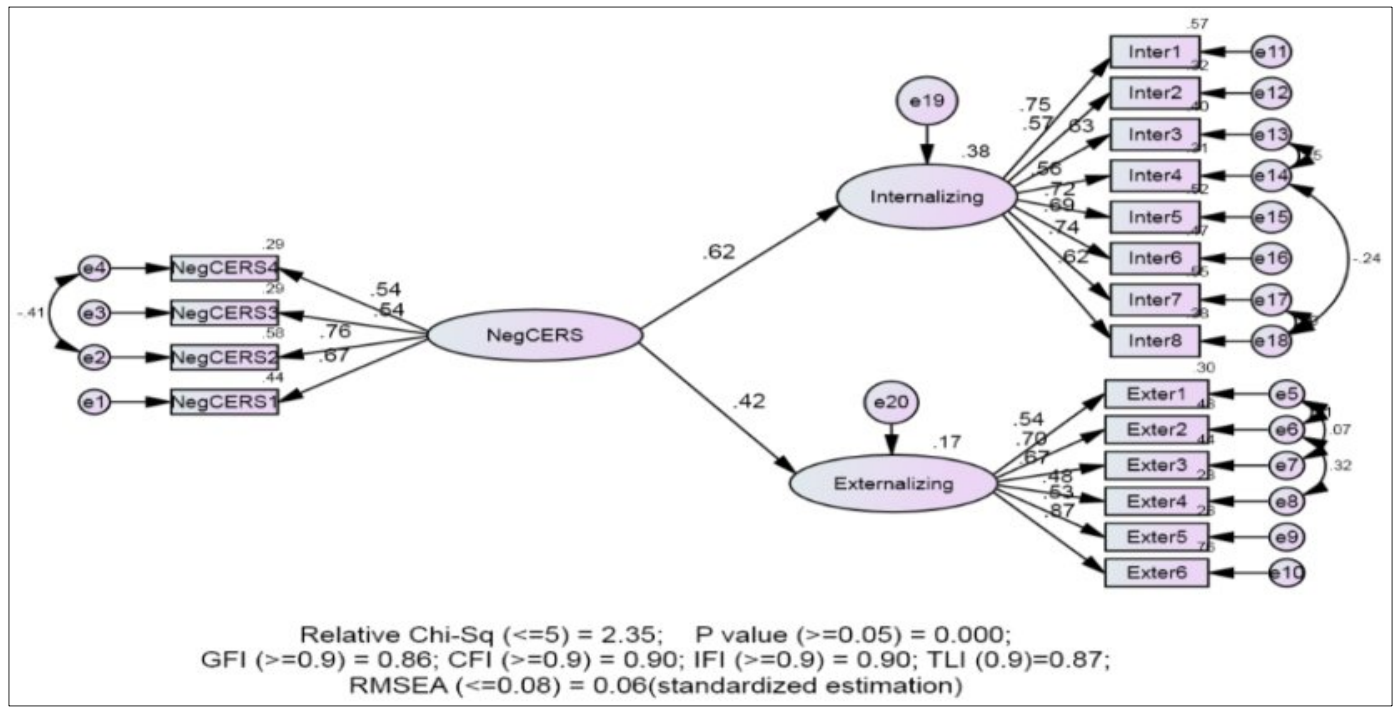

Figure 4. Model fit for males

\section{Discussion}

Although Zelomke and Hahn (2010) reported that boys use other blame strategy more than girls and, consequently, this issue lead boys toward externalizing more than girls. In the present study there was no significant difference between two genders in this area. Also according to Zelomke and Hahn (2010) females utilize putting into perspective strategy more than males, thus, they suffered from internalizing and externalizing less than males. However, the results of the present 
Journal of Educational, Health and Community Psychology

study, as well as Karim et al (2014), did not support this suggestion.

Furthermore, the results of the present study can be implied as a confirmation for Garnefski et al (2001) suggestion, who claimed CERS are due to nurture, not nature. Also, Garnefski, Rieffe, Jellesma, Terwogt, and Keraaij (2007) claimed that children do not have emotional regulation strategies base on cognitive systems. They suggested children, after nine years old, learn to use their own cognitive process to regulate their emotions according to the nurturing and educational environment they involved.

Similarly, Moyal, Henik, and Anholt (2013) reported negative CERS as the learnt psychopathological methods to encounter stress events. Accordingly, the results of present research showed that gender cannot increase or decrease the potential readiness of adolescents to use one strategy more or less than the other strategies. This conclusion magnifies the importance of nurture and education role in developing positive CERS and preventing negative CERS. According to the output of this research, parents, as well as other educational authorities, have the main responsibility to construct positive strategies and to prevent the developing of negative strategies in children and adolescents cognitive system.

\section{Conclusion}

Prior studies mentioned that females have twice rates of internalizing compared to males, (Graves, Kaslow, \& Frabutt, 2010; Zlomke \& Hahn, 2010; Silverman \& Field, 2011); however, most of previous studies on CERS did not report significant differences in utilizing negative and positive CERS among two genders. In the present study also, gender could not moderate the relationship between positive and negative CERS and IEBP among the adolescents between 12 and 19. The finding suggest that positive CERS can be consider as a protective factor against both internalizing and externalizing behavioral problems in male and female adolescents equally. Also, according to the results, negative CERS is considered as a risk factor for internalizing and externalizing behavioral problems among adolescents.

The limitation of present study is due to the limited sample in this study. It would be better if for the future research is conducted with more representative sample, and also to test in different countries. Also it is suggested to design an experimental research to elaborate the role of positive CERS training, as a protective 
Journal of Educational, Health and Community Psychology

factor against IEBP in adolescents' mental health.

\section{References}

Abdollahi, A., Talib M. A., Yaacob S. N., \& Ismail, Z. (2015). Problem-solving skills appraisal mediates hardiness and suicidal ideation among malaysian undergraduate students. US National Library of Medicine National Institutes of Health (PUBMED)10(4).

Emami, H., Ghazinour, M., Rezaeishiraz, H., \& Richter, J. (2007). Mental health of adolescents in Tehran, Iran. Journal of Adolescent Health, 41(6), 571-576.

Erk, S., Mikschl, A., Stier, S., Ciaramidaro, A., Gapp, V., Weber, B., \& Walter, H. (2010). Acute and sustained effects of cognitive emotion regulation in major depression. The Journal of neuroscience, 30(47), 15726-15734.

Fakhari, A., Ranjbar, F., Dadashzadeh, H., \& Moghaddas, F. (2007). An epidemiological survey of mental disorders among adults in the north, west area of Tabriz, Iran. Pak J Med Sci January-March, 23(1), 54-58.

Garnefski, N., Kraaij, V., \& Spinhoven, P. (2001). Negative life events, cognitive emotion regulation and emotional problems. Personality and Individual Differences, 30(8), 2340.

Ganefski, N., Rieffe, C., Jellesma, F., Terwogt, M., \& kraaij (2007). Cognitive Emotional Regulation Strategies an Emotional Problems in 9-11 years old chilren. Eur Adoles Psyhiatry, 16 (1), 1-9.

Gartner, R. (2011). Sex, gender, and crime. New York: Pelican Press.

Graves, K.N., Kaslow, N.J., \& Frabutt, J.M. (2010). A culturally-informed approach to trauma, suicidal behavior, and overt aggression in African American adolescents. Aggression and Violent Behavior, 15(1), 36-41.

Hall, R. J., Snell, A. F., \& Foust, M. S. (1999). Item parceling strategies in SEM: Investigating the subtle effects of unmodeled secondary constructs. Organizational Research Methods, 2(3), 233-256.

Karim, A.K.M., Rezaul, S. T., \& Mahmud, A.Y. (2014). Cognitive emotion regulation in children as related to their parenting style, family type and gender. Journal of the Asiatic Society of Bangladesh, Science, 39(2), 211-220.

Kim-Spoon, J., Cicchetti, D., \& Rogosch, F. A. (2013). A longitudinal study of emotion regulation, emotion lability-negativity, and internalizing symptomatology in maltreated and non maltreated children. Child development, 84(2), 512-527. 
Journal of Educational, Health and Community Psychology

Lei, M-K., Simons, R. L., Simons, L. G., \& Edmond, M. B. (2014). Gender equality and violent behavior: How neighborhood gender equality influences the gender gap in violence. Violence and victims, 29(1), 89.

Little, T. D., Cunningham, W. A., Shahar, G., \& Widaman, K. F. (2002). To parcel or not to parcel: Exploring the question, weighing the merits. Structural equation modeling, 9(2), 151-173.

Markus, K. A. (2012). Principles and practice of structural equation modeling by Rex B. Kline. Structural Equation Modeling: A Multidisciplinary Journal, 19(3), 509-512.

McRae, K., Ochsner, K.N., Mauss, I.B., Gabrieli, J.J.D., \& Gross, J.J. (2008). Gender differences in emotion regulation: An fMRI study of cognitive reappraisal. Group Processes \& Intergroup Relations, 11(2), 143-162.

Monika, M., Marianna, S., Tamas, M., Elvira, G., \& Dora, P. F. (2013). Cognitive emotion regulation strategies moderate the effect of parenting self-eficacy beliefs on parents' anxiety folowing their child's surgery. Journal of Pédiatrie Psychology, 38(4), 462471.

Moyal, N., Henik, A., \& Anholt, G. (2013). Cognitive Strategies to Regulate EmotionCurrent Evidance and Future Direction. Front Psychology.vol 4. 10-19.

Muller, R. T., Vascotto, N. A., Konanur, S., \& Rosenkranz, S. (2013). Emotion regulation and psychopathology in a sample of maltreated children. Journal of Child \& Adolescent Trauma, 6(1), 25-40. doi: 10.1080/19361521.2013.737441.

Oshri, A., Rogosch, F.A., Burnette, M.L., \& Cicchetti, D. (2011). Developmental pathways to adolescent cannabis abuse and dependence: Child maltreatment, emerging personality, and internalizing versus externalizing psychopathology. Paper presented at the Psychology of Addictive Behaviors, USA.

Samani, S., \& Sadeghi, L. (2010). بررسى كفايت رو انسنجى برسشنامه تنظيم شناختى هيجانى. روشهاو مدلهاى رو انشناختى, ?, ??-? (20)

Silverman, W. K., \& Field, A. P. (2011). Anxiety disorders in children and adolescents: Cambridge University Press.

Wright, A., Jorm, A. F., \& Mackinnon, A. J. (2011). Labeling of mental disorders and stigma in young people. Social Science \& Medicine, 73, 498-506.

Zlomke, K. R., \& Hahn, K.S. (2010). Cognitive emotion regulation strategies: Gender differences and associations to worry. Personality and Individual Differences, 48(4), 408-413. 
Journal of Educational, Health and Community Psychology

Vol 5, No 1, 2016.

Vahid Momtaz, Mariani, Mansor, Rojanah 